\title{
Treatment with an Anti-CK2 Synthetic Peptide Improves Clinical Response in COVID-19 Patients with Pneumonia. A Randomized and Controlled Clinical Trial
}

Leticia R. Cruz 1,‡, Idania Baladrón 2,‡, Aliusha Rittoles ${ }^{1}$, Pablo A. Díaz ${ }^{2}$, Carmen Valenzuela ${ }^{3}$, Raúl Santana ${ }^{1}$, Maria M. Vázquez ${ }^{2}$, Ariadna García ${ }^{1}$, Deyli Chacón ${ }^{1}$, Delvin Thompson ${ }^{1}$, Gustavo Perera ${ }^{1}$, Ariel González ${ }^{4}$, Rafael Reyes ${ }^{5}$, Loida Torres ${ }^{4}$, Jesus Pérez ${ }^{1}$, Yania Valido ${ }^{1}$, Ralysmay Rodriguez ${ }^{1}$, Dania M. Vázquez-Bloomquist ${ }^{2}$, Mauro Rosales 2,6, Ailyn C. Ramón 2, George V. Pérez 2, Gerardo Guillén 2, Verena Muzio ${ }^{2}$, Yasser Perera ${ }^{2,7}$, and Silvio E. Perea ${ }^{2,{ }^{*}}$ for the ATENEA-Co-300 group *

Affiliations: ${ }^{1}$ Central Hospital "Luis Diaz Soto", Havana 19130, Cuba, ${ }^{2}$ Center for Genetic Engineering and Biotechnology, Havana 10600, Cuba, ${ }^{3}$ Center for Molecular Immunology, Havana 11600, Cuba, ${ }^{4}$ International Center of Health "La Pradera", Havana 11600, Cuba, ${ }^{5}$ National Institute of Oncology and Radiobiology, Havana 10400, Cuba, ${ }^{6}$ Faculty of Biology, University of Havana, Havana 10400, Cuba, ${ }^{7}$ China-Cuba Biotechnology Joint Innovation Center (CCBJIC), Yongzhou Zhong Gu Biotechnology Co., Ltd, Hunan 425000, China.

\section{Table of Content}

Data

Page Number

1. Table S1 (Chest-CT evolution considering lesion's extent)...........S-2 


\section{Table S1: Chest-CT evolution considering lesion's extent}

\begin{tabular}{|c|c|c|c|c|c|}
\hline & & Group & I & II & Sign. (U- \\
\hline & & $\mathrm{N}^{*}$ & 7 & 9 & $\begin{array}{c}\text { Mann } \\
\text { Whitney) }\end{array}$ \\
\hline & Day 0 & Median \pm RI & $4.5 \pm 10.0$ & $2.0 \pm 5.0$ & 0.146 \\
\hline Lesion's extent & & (Min; Max) & $(0 ; 18)$ & $(0 ; 6)$ & \\
\hline (Score 1-5) & Day 7 & Median \pm RI & $3.5 \pm 10.0$ & $2.0 \pm 3.0$ & 0.189 \\
\hline & & (Min; Max) & $(0 ; 15)$ & $(0 ; 6)$ & \\
\hline & & Sign. (Wilcoxon) & 0.066 & 1.000 & \\
\hline Reduction of les & extent & YES & $4(66.7 \%)$ & $1(14.3 \%)$ & 0.103 \\
\hline & & $\mathrm{NO}$ & $2(33.0 \%)$ & $6(85.7 \%)$ & (Fisher) \\
\hline & & Dif. (IC 95\%) & $53.2(3$ & ;86.8) & Bayesian \\
\hline & & $P($ Dif. $>0)$ & & & analysis \\
\hline
\end{tabular}

* Per protocol population defined as patients who completed the regimen originally allocated and patients having chest-CT at the beginning and at the end of treatment 